\title{
The buckling analysis of a cold-formed steel C-sectional column resting on an elastic foundation
}

\author{
Patryk Deniziak ${ }^{1, *}$ and Piotr Iwicki $^{1}$ \\ 1 Gdańsk University of Technology, Faculty of Civil and Environmental Engineering, \\ Narutowicza 11/12, 80-233 Gdańsk, Poland
}

\begin{abstract}
The paper is focused on stability analysis of different models of steel cold-formed C-section column. The analysed element may be applied as a primary load-bearing member in steel trusses or silo columns. The column can be used as a support for a wall of roof plates made of corrugated sheets. The wall sheeting that restrains the column against buckling may be considered as an elastic foundation. Due to the design solutions the foundation may be modelled as a series of lateral translational or rotational elastic supports. Such model is used for example in silo column analysis. In the paper linear bifurcation analysis (LBA) of axially compressed columns with different type of elastic foundation is carried by means of ABAQUS software. The analysed thin-walled column $(\mathrm{C} 250 \times 100 \times 33 \times 4)$ is regarded as a load-bearing element in a steel hall. The column was modelled by shell elements, the foundation modelled by means of elastic supports. The column length was $5000 \mathrm{~mm}$. The authors present a 3D image of an influence of lateral translational and rotational elastic supports on the buckling resistance of the column.
\end{abstract}

\section{Introduction}

In modern steel structures cold-formed elements are no longer used only as secondary sections like roof purlins or wall girts. Many companies patented their own systems that allow to erect complete steel halls including major beams, lattices and columns using only thin-walled sections. The cold-formed element stiffness is smaller than its hot-rolled equivalent what may have an effect on global stability of these slender members, the effect is described in more detail in articles $[6,10]$. Consequently, the presence of adjacent elements is taken into account in order to increase the stiffness. The wall or roof sheeting can be analysed as an involved structural part as presented in articles [2,8]. This approach to the issue is theoretically easy to apply but practically complicated to verify.

The authors have chosen a thin-wall cross-section that is implemented by an international steel structure manufacturer. They decided to analyse the elastic foundation influence on a member resistance. The paper is focused on stability analysis of various models of steel cold-formed C-section column. The analysed element may be also applied

\footnotetext{
*Corresponding author: patdeniz@pg.edu.pl
} 
as a primary load-bearing member in steel trusses or silo columns. This column can be also used as a support for a wall or roof plates made of corrugated or trapezoidal sheets.

\section{Issue description}

The wall sheeting that restrains the column against buckling may be considered an elastic foundation located along the element web. Due to the design solutions the foundation may be modelled in the form of lateral translational or rotational elastic supports. This approach is well-known in the process of silo column design $[5,7,9]$, included in the EC 1993-4-1 [4].

The analysed thin-walled column cross-section (C $250 \times 100 \times 33)$ is shown in - Figure 1a. The authors assumed the thickness of the element wall equal to $4.0 \mathrm{~mm}$. The element is $5000 \mathrm{~mm}$ high and the location and types of the elastic supports are presented in Figure 1b.

a)

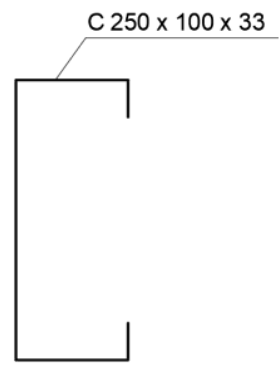

b)

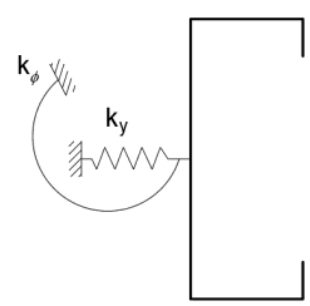

Fig. 1. The a) analysed built-up column cross-section, b) location of elastic supports.

The procedure of determining the elastic foundation stiffness provided by wall sheeting is shown in Figure 2.

a)

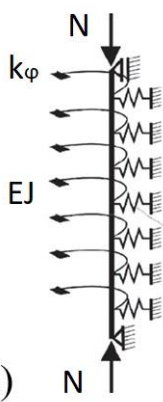

b) $k_{y}$

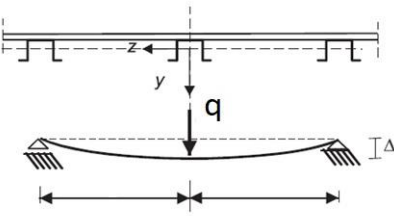

c) $k_{\phi}$

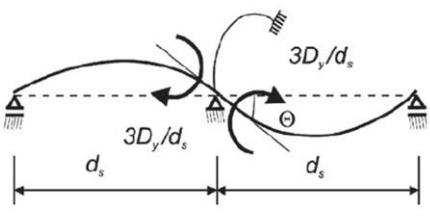

Fig. 2. Thin walled column resting on elastic foundation provided by wall sheets, (a) axially compressed column supported by elastic foundation in lateral direction, stiffness determination of elastic foundation in (b) lateral and (c) rotational direction.

In the paper linear bifurcation analysis (LBA) of axially compressed columns with different types of elastic foundation is carried out using ABAQUS [1] software. Elastic S350 GD+Z steel material was used, according to the EC 1993-1-3 [3]. A column double hinged static scheme is assumed. Top edge shell load is applied of a $1000 \mathrm{~N}$ resultant force. 
The column was modelled by 11.322 shell S4R elements, the foundation modelled by means of point elastic supports. The web arrangement of 17 point lateral translational and rotational elastic supports (spaced every $312,5 \mathrm{~mm}$ due to the location of connectors) is presented in Figure 3. The top and bottom edge boundary conditions are marked in a Figure 3 too (the restrained degrees of freedom are highlighted). While the shape variation of the lower edge cross-section is restrained the situation resembles the case of a welded bottom plate. Blocking the possibility of changing the shape of the lower edge cross-section is corresponding to the actual support in the case of welded bottom plate.

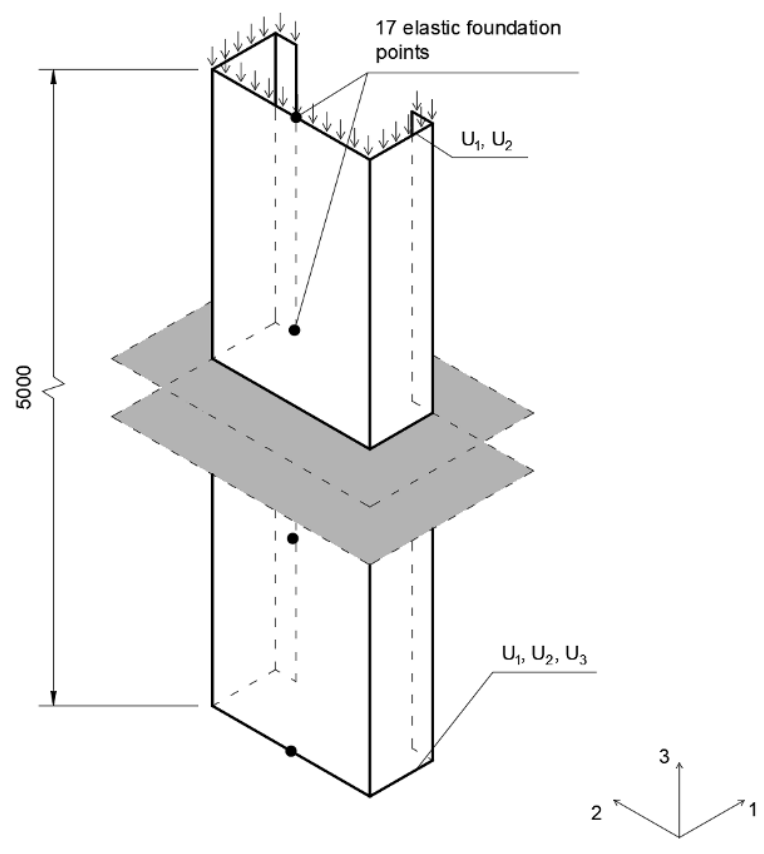

Fig. 3. The web arrangement of point elastic support and restrained degrees of freedom for element top and bottom edges.

In the case of column restraining by steel sheeting between two other columns (Figure $2 \mathrm{~b}$ and $2 \mathrm{c}$ ) the lateral translational and rotational stiffness can be compared to simple computational situations commonly known in structural mechanics as a slope and deflection method (Figure 4). A doubled reaction from two adjacent columns (for displacement or rotation equal to one) can be compared to the steel sheeting stiffness assuming rigid connection to the column. 

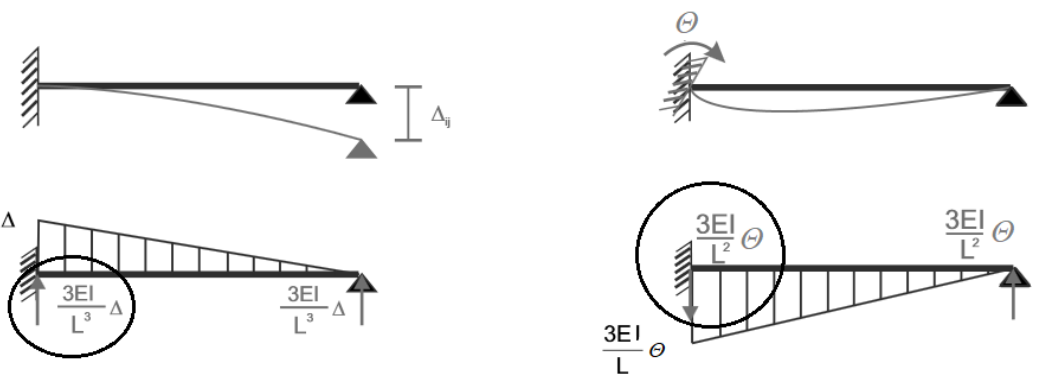

Fig. 4. The slope and deflection method computational situations of the assumed schematic scheme.

\section{Results}

\subsection{Relation between foundation stiffness and the critical load}

Several combinations of a different $k_{y}$ and $k_{\phi}$ stiffness values were taken into account. The Abaqus linear bifurcation analysis provided suitable critical load factor for each combination.

Figures 5 and 6 present the evolution of buckling critical load of the column related to the point foundation stiffness. Increasing the lateral stiffness $\left(k_{y}\right)$ of the foundation column enhances the column load capacity, that stabilizes at the level of $350 \mathrm{kN}$. Reaching lateral stiffness $\left(k_{y}\right)$ equal to $100 \mathrm{~N} / \mathrm{mm}$ provides the most effective stiffening. Furthermore, while changing the rotational $\left(k_{\phi}\right)$ stiffness alone does not affect the column resistance. Subsequently, the authors conducted a combined analysis to check the interaction between the lateral $\left(k_{y}\right)$ and rotational $\left(k_{\phi}\right)$ stiffness related to the total critical load value, what is presented on 3D graph in Figure 7.

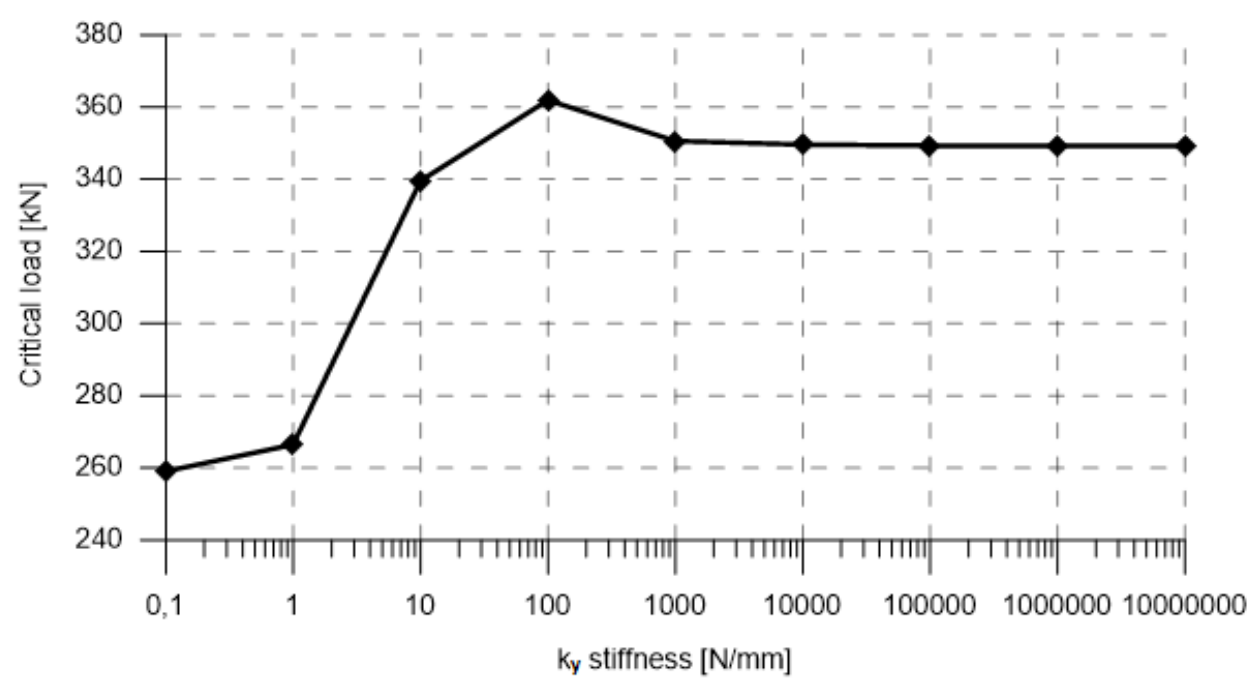

Fig. 5. Critical load dependence on $k_{y}$ lateral stiffness change $\left(k_{\phi}=0\right)$. 


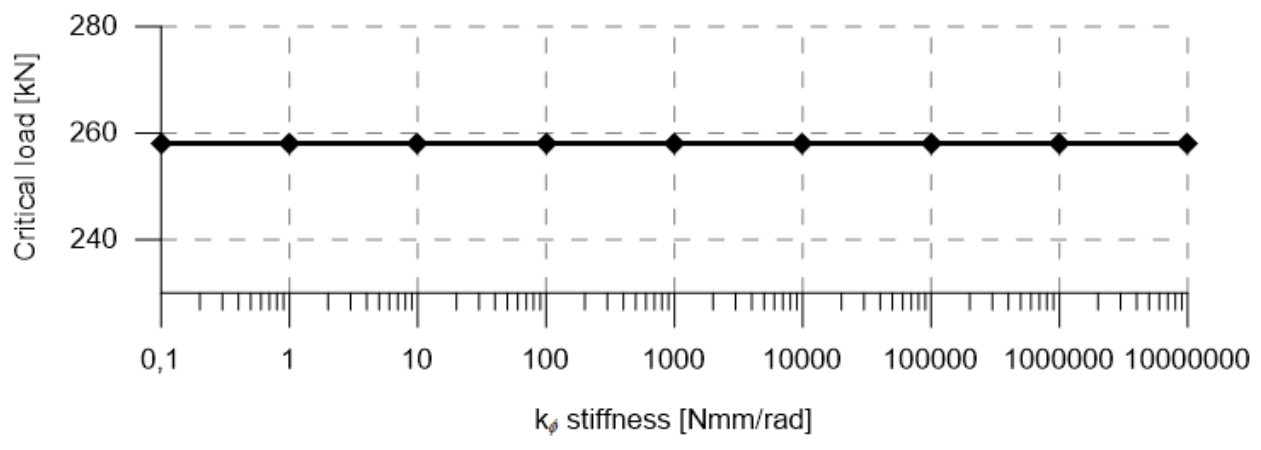

Fig. 6. Critical load dependence on $k_{\phi}$ rotational stiffness change $\left(k_{y}=0\right)$.

An existing steel wall or roof sheeting is characterized by both lateral and rotational stiffness. The combination of these two stiffnesses together gives higher critical load than single factor analysis especially after reaching $1.000 \mathrm{~N} / \mathrm{mm}$ and $10.000 \mathrm{Nmm} / \mathrm{rad}$. Exceeding the values of $10.000 \mathrm{~N} / \mathrm{mm}$ and $1.000 .000 \mathrm{Nmm} / \mathrm{rad}$ does not improve the column resistance. Local buckling occurs the column walls, thus further stiffening is not effective anymore.

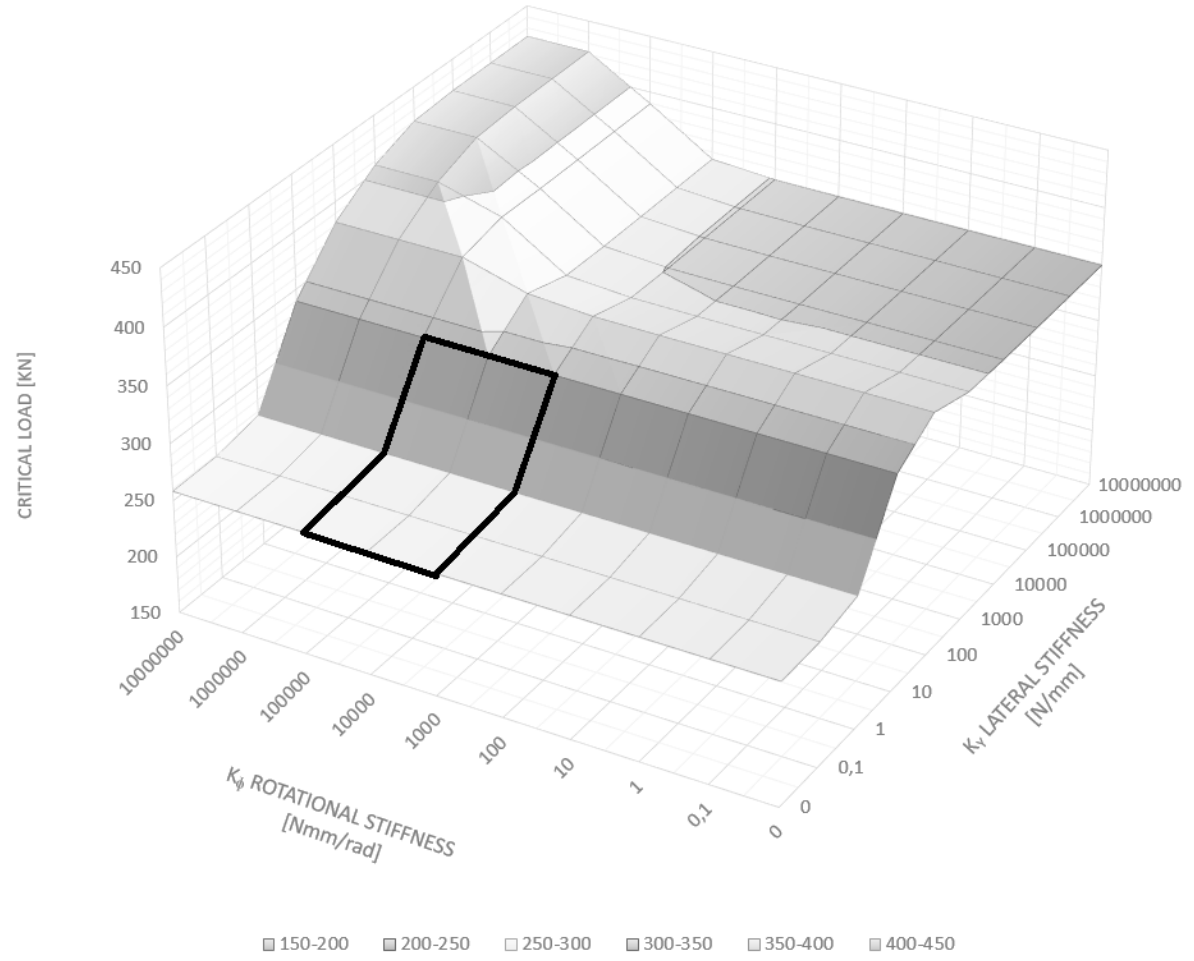

Fig. 7. 3D representation of combined critical load dependent on the lateral and the rotational stiffness. 


\subsection{Relation between foundation stiffness and the buckling forms}

While changing lateral and rotational stiffness different forms of stability loss were observed: flexural, torsional and local buckling appeared.

In the case of-low lateral stiffness $\left(k_{y}\right)$ of the column foundation a global flexural buckling mode was obtained. For a higher foundation stiffness rotational buckling modes were observed. The change in rotational $\left(k_{\phi}\right)$ stiffness alone does not influence the flexural buckling form until both factors are combined together. Increasing both stiffnesses leads ultimately to over-stiffening and the element buckles locally. The combined relation between the foundation stiffnesses and the buckling forms is shown in a Table 1.

\subsection{Selected wall sheeting stiffness checking}

The authors selected two trapezoidal sheeting cross-sections (TR $18.124 .868 \mathrm{t}=0.50 \mathrm{~mm}$ and TR 55.235.940 $\mathrm{t}=1.0 \mathrm{~mm}$ ) to check a practical range of the stiffness. A moment of inertia for steel sheeting was calculated accordingly to the distance between points where an elastic foundations was applied making the results comparable with the previous assumptions of elastic point foundation. The obtained practical stiffness range is marked in Figure 7 with a black thick line and bold in Table 1.

The ordinary sheeting application increases the analysed column resistance by $32 \%$. Also the buckling form is changing. Thicker and bigger trapezoidal sheeting can prevent against global deformation. This information can be profitable for manufacturers dealing with steel hall erection.

Table 1. Combined relation between the foundation stiffnesses and the element buckling forms.

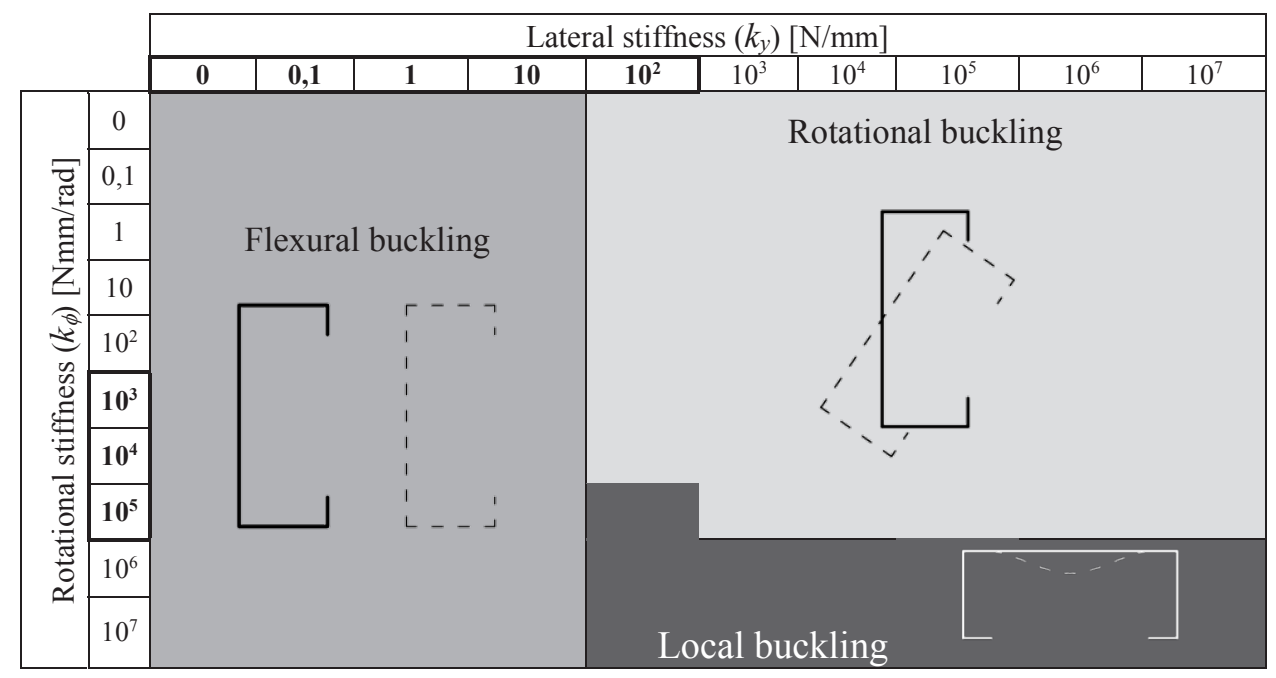

In the upcoming future the authors plan to check other thin-walled columns making the cross-section thickness and the height variable, thus creating a set of clues for designers. The model will be developed and the sheeting will be implemented as a full-scale shield shell Abaqus-based model [1]. It is also planned to analyse a build-up cross-section of C-profile with battens connecting the chords.

In the opinion of the authors the topic seems to be serviceable and perspective as evidenced by numerous state-of-the-art publications of this kind. 


\section{References}

1. ABAQUS, Theory Manual, Version 6.8, Hibbit, Karlsson \& Sorensen Inc (2008)

2. C. Basaglia, D. Camotim, R. Gonçalves, A. Graçab, GBT-based assessment of the buckling behaviour of cold-formed steel purlins restrained by sheeting, Thin-Walled Structures, 72 (2013)

3. EN 1993-1-3, Eurocode 3: Design of steel structures - Part 1-3: General rules Supplementary rules for cold-formed members and sheeting

4. EN 1993-4-1, Eurocode 3: Design of steel structures. Part 4-1: Silos.

5. P. Hajko, J. Tejchman, M. Wójcik, Investigations of local/global buckling of cylindrical metal silos with corrugated sheets and open-sectional column profiles, Thin-Walled Structures 123 (2018)

6. Y. Lu, W. Li, T. Zhou, H. Wu, Novel local buckling formulae for cold-formed C-section columns considering end condition effect, Thin-Walled Structures 116 (2017)

7. K. Rejowski, P. Iwicki, Buckling analysis of cold formed silo column, Mechanics and Mechanical Engineering 20 (2016)

8. J. Santos Franco, E. Miranda Batista, Buckling behavior and strength of thin-walled stiffened trapezoidal CFS under flexural bending, Thin-Walled Structures 117 (2017)

9. M. Wójcik, P. Iwicki, J. Tejchman, 3D buckling analysis of a cylindrical metal bin composed of corrugated sheets strengthened by vertical stiffeners, Thin-Walled Structures 49 (2011)

10. X. Zhou, Z. Liu, Z. He, General distortional buckling formulae for both fixed-ended and pinned-ended C-section columns, Thin-Walled Structures 94 (2015) 